\title{
Constitución y género o la inconclusa igualdad de las mujeres Constitution and gender or the unfinished equality of women
}

\author{
Cristina Sánchez Muñoz \\ Universidad Autónoma de Madrid \\ ORCID ID 0000-0003-3925-2363 \\ cris.sanchez@uam.es
}

\section{Cita recomendada:}

Sánchez Muñoz, C. (2019). Constitución y género o la inconclusa igualdad de las mujeres. Eunomía. Revista en Cultura de la Legalidad, 17, 377-381.

doi: https://doi.org/10.20318/eunomia.2019.5041

Recibido / received: 09/09/2019

«Y nosotras también somos ciudadanas». Así se manifestaba una de las ilustradas francesas, Mademoiselle Jodin, en 1790, al dirigirse a la Asamblea Nacional para pedir un proyecto de legislación para las mujeres (Puleo, 1993, p. 144). El trabajo de Itziar Gómez Fernández se inscribe en una larga línea argumentativa que se remonta a la configuración de las democracias contemporáneas. Por tanto, no estamos al hablar de "constitución y género», ante una moda académica o ante una respuesta al albur de otros posibles cambios constitucionales, sino que tiene más calado y más largo alcance. Por consiguiente, creo que es necesario trazar para los posibles lectores y lectoras, los caminos por los que ha transitado un debate que no es inédito, sino que se inserta en un marco teórico e histórico que afecta en realidad a la democracia y a la igualdad de derechos.

No es nuevo señalar que en las formulaciones y las reformulaciones de las democracias contemporáneas las demandas de las mujeres por su inclusión en un contrato social que se plasma a nivel constitucional, han sido una constante desde la Ilustración. Un texto tan relevante como La declaración de los derechos de la mujer y de la ciudadana, de Olympe de Gouges, en 1791, ya señalaba las exclusiones de facto de las mujeres (Sánchez, 2001) El pretendido universalismo de los derechos y la ciudadanía nacía ya como un "universalismo sustitucionalista», en los términos actuales de Seyla Benhabib, esto es, presentando como universal el consenso ideal de selves definidos ficticiamente, identificando las experiencias de un grupo 
específico de sujetos -los varones- como el caso paradigmático de los humanos como tales (Benhabib, 1992). Pero, además, dicho universalismo no sólo sería sustitucionalista, sino también excluyente respecto aquellos otros sujetos que, como las mujeres -aunque no sólo- no comparten las características requeridas para su inclusión en el ámbito público. La cuestión, por tanto, no radica únicamente en la inclusión sin más de las mujeres dentro del mismo marco epistemológico, sino que dicha exclusión nos mostraría las deficiencias de ese mismo marco (Benhabib, 1992). Los posteriores desarrollos históricos de las democracias siguieron mostrando con crudeza la ceguera hacia la inclusión de las mujeres en una ciudadanía plena. Cuando las sufragistas exigían el derecho al voto, o más adelante, las feministas de los años setenta demandaban los derechos sociales, no estaban reclamando simplemente ser admitidas en un estatus preexistente, sino que, en realidad, desafiaban todo el orden político, social y jurídico, señalando la necesidad de reformular nuestra gramática política y jurídica. De este modo, cuestiones como las críticas al sujeto independiente y abstracto como modelo del ciudadano, la distinción entre trabajo productivo o reproductivo o el papel de la familia y el cuidado en la ciudadanía, son expuestas por parte de la teoría feminista contemporánea como elementos relevantes a la hora de repensar la democracia, lo político y la ciudadanía.

Sin embargo, este "déficit epistemológico" (Benhabib, 1992) nos conduce a lo que Carole Pateman ha denominado el "dilema Wollstonecraft», presente en el intento de las mujeres de conseguir una ciudadanía plena. Este dilema representaría la encrucijada ante dos demandas incompatibles: por un lado, reclamar la ciudadanía dentro del actual marco androcéntrico y, por el otro, resaltar las capacidades específicas y las necesidades de las mujeres que deberían ser reconocidas en el espacio público. Las dos alternativas son incompatibles, sostiene Pateman, ya que o las mujeres se adaptan a lo que no son -varones- $y$ entonces pueden ser ciudadanas plenas o continúan demandando el reconocimiento de sus capacidades y aportaciones para forjar la ciudadanía, pero eso, precisamente, es lo que la ciudadanía pretendidamente neutral excluye (Pateman, 1995).

Por su parte, el feminismo jurídico también ha enfrentado los avatares del mencionado dilema: un enfoque de igualación, incorporacionista o integracionista (Scales, 1986), encuentra dificultades, por ejemplo, para asimilar diferencias específicas en el terreno de los derechos sexuales y reproductivos, pues supone incorporarse a un lenguaje y a unas categorías ya constituidas, elaboradas en función de las experiencias de los varones. Es a partir de los años ochenta, cuando se comienza a explorar el otro cuerno del dilema, esto es, el reconocimiento de las diferencias, cuestionando el derecho y las instituciones jurídicas no por la incorrecta aplicación de las leyes, sino por su sesgo masculino bajo una aparente neutralidad (Costa, 2016).

Por lo tanto, plantear la oportunidad de una reforma de la Constitución desde una perspectiva de género se conecta y se sitúa, en buena medida, dentro de una genealogía de vindicaciones consustancial al feminismo moderno, pero también, enfrentándose a sus dilemas internos. En nuestro país, el debate tampoco es nuevo; se desarrolla con unos antecedentes que entroncan directamente con el debate acerca de la paridad -cuestión que como no podía ser menos, también recoge Itziar Gómez- Desde 1992, año en el que se adopta en la primera Cumbre Europea "Mujeres en el poder" la llamada Declaración de Atenas, en favor de la democracia paritaria («participación equilibrada de mujeres y hombres en las posiciones de poder y de toma de decisiones»), se abre en España la discusión teórica -y política- acerca de la extensión de la democracia en favor de las medidas de acción afirmativa. "Son las cuotas, pero no son sólo las cuotas», señala acertadamente Itziar Gómez Fernández en su texto. Y, efectivamente, la propuesta de una democracia paritaria no 
se limita a las cuotas, de la misma manera que la democracia representativa no es la urna únicamente. Implica la revisión y construcción de un nuevo contrato social fundante en el que estén incluidas las mujeres, en ese reclamo ilustrado de «también somos ciudadanas». Al igual que en la citada Declaración de Atenas, Itziar Gómez también utiliza el argumento utilitarista que ya usase Stuart Mill en su defensa de la inclusión de las mujeres en los derechos de ciudadanía: la inclusión de los talentos de la mitad de la humanidad colaborará en el progreso de nuestras sociedades, al sumar dichos talentos. El otro argumento es el del reconocimiento y constatación de la desigualdad -más bien de la invisibilidad y ausencia de las mujeres- del momento del pacto social constituyente, y la necesidad de restañar esa herida originaria, precisamente mediante el reconocimiento de esa desigualdad. Podríamos añadir otros argumentos, como el que expone Anne Phillips al hablar de la necesidad de una «política de la presencia», señalando que la pregunta acerca de «quien habla en nombre de quién» es relevante, si tenemos en cuenta la composición de los parlamentos y los espacios de toma de decisiones. Una política de la presencia, en este sentido, frente a una "política de las ideas», garantizaría la presencia en la deliberación pública de aquellos sujetos, como las mujeres, cuyas experiencias compartidas no son habitualmente escuchadas, ni tan siquiera vistas o percibidas (Phillips, 1995). Pensemos en este terreno, por ejemplo, la polémica que se ha suscitado cuando alguna diputada ha amamantado a su hijo en el Parlamento, tanto en nuestro país como en otros.

En esta línea de defensa de la democracia paritaria en nuestro país, cabe destacar el trabajo que llevan realizando, desde hace ya más de una década, las académicas integrantes de la Red Feminista de Derecho Constitucional (RFDC) ${ }^{1}$, donde también se ubica el trabajo de Itziar Gómez Fernández, y en el seno de la cual, obras pioneras como las de Julia Sevilla respecto a la incorporación de la perspectiva de género en la Constitución y el desarrollo de la democracia paritaria han sido un referente para estas cuestiones (Sevilla, 2004). Igualmente, hay que destacar el trabajo realizado por la Red en la elaboración de materiales docentes de Derecho Constitucional desde la perspectiva de género. En definitiva, un trabajo académico, docente e investigador con una ya larga trayectoria que acredita un debate continuado y riguroso en nuestro país, del que forma parte la obra de Itziar Gómez.

En oposición a lo que la autora denomina «mitos paralizantes» frente a una reforma constitucional y, en mi opinión, presentes no sólo en una reforma feminista, sino en cualquier otro tipo de reforma de la Constitución (el mito «de la caja de Pandora», el de «la ausencia de necesidad», y el del «consenso imprescindible»), nos propone lo que ella denomina «mitos inspiradores» para llevar a cabo la reforma desde una perspectiva de género: el mito de «la voz feminista como voz constituyente», el de «la coeducación como base del cambio» y, por último, el mito de «la democracia paritaria». Seguramente, hubiese sido más recomendable no utilizar en estos tres últimos el término «mito», pues más bien hacen referencia a propuestas de lege ferenda, y la palabra «mito», por el contrario, sugiere más bien una referencia a un pasado ya acaecido, y no a un futuro por venir. El primero de ellos («La voz feminista como voz constituyente») se hace eco de los cambios sociales de los últimos años a favor de un mayor reconocimiento de los derechos de las mujeres. Si en 1978 las constituyentes, como nos han recordado recientemente tanto Oliva Acosta como Magis Iglesias², no alcanzaron «masa crítica» para incorporar referencias a la igualdad de las mujeres, la situación actual dista mucho de ser la misma, con el mayor número de mujeres electas, un 47,7\%, en las elecciones del

\footnotetext{
${ }^{1}$ http://www.feministasconstitucional.org

2 Oliva Acosta elaboró en el 2008 el documental Las constituyentes (http://wwww.lasconstituyentes.org), y Magis Iglesias ha publicado Fuímos nosotras. Las primeras parlamentarias de la democracia, Ed. Debate, Madrid, 2019, donde entrevista a las veintisiete diputadas de la primera legislatura.
} 
pasado mes de Abril, lo que nos sitúa en el sexto país del mundo con más diputadas. Pero además de ese muy notable incremento, pero también como reflejo de ello, es cierto que en la actualidad la igualdad entre mujeres y hombres aparece ya enraizada socialmente entre los valores que nos definen como sociedad. Y esa igualdad presenta ramificaciones (empleo, salud, participación, educación...) que resultan insuficientes en su abordaje con los mimbres constitucionales conocidos: art. 14 y 9.2 CE. Asimismo, la concreción de la igualdad de género es ya una realidad en la normativa internacional: desde la CEDAW hasta la Agenda 2030 de Naciones Unidas, donde este principio aparece transversalmente en los 17 objetivos propuestos.

Por consiguiente, con esta propuesta de reforma, la Constitución haría suya no sólo un importante cambio social, sino también una realidad normativa recogida ya internacionalmente. Se reformularía y ampliaría el pacto constituyente, tanto en lo que se refiere a los sujetos constituyentes, en términos de democracia paritaria, como en lo que respecta a los contenidos recogidos en el texto constitucional. Respecto a lo primero, a la inclusión paritaria de las mujeres, cabe recordar en ese sentido, que las mujeres no constituyen un grupo más, sino que están presentes en todos los grupos sociales, al igual que los varones (Osborne, 1996). En cuanto a lo segundo, a la inclusión de nuevos contenidos, la propuesta de Itziar Gómez concreta esos derechos, señalando la necesidad -que comparto- de constitucionalizarlos. En su propuesta, podemos observar tanto una estrategia integracionista como también una estrategia diferenciadora, según comentábamos con anterioridad, desde la perspectiva del feminismo jurídico. Propone, en este sentido, con un carácter más asimilacionista, la paridad en el reparto de poder, la igualdad en el ámbito laboral, la presencia equilibrada en el CGPJ y en el TC, y el derecho a una vida libre de violencia. Entre las propuestas de carácter más diferenciador, esto es, que tienen en cuenta las características concretas, encarnadas, del sujeto mujer y de los roles de género asignados a este, tendríamos el derecho a la conciliación de la vida personal, familiar y laboral y los derechos sexuales y reproductivos.

Las otras dos propuestas («La coeducación como base del cambio», y «La democracia paritaria») completarían esta agenda de inclusión de la perspectiva de género en la CE. En este repaso de las propuestas de la autora, he echado de menos, sin embargo, una mayor incidencia en lo que, a mi juicio, constituye una novedad en este debate de incorporación de las mujeres a la Constitución, y es la ampliación del pacto constitucional respecto a los temas relacionados tradicionalmente con la esfera privada. Así, cuestiones como los derechos sexuales y reproductivos, la integridad física, o la conciliación, aparecen en el debate jurídico feminista reciente, subrayando los principios de autonomía e igualdad (Bergallo, 2011). Si bien la profundización de la presencia de las mujeres en la esfera pública ha sido la línea clásica de vindicación del feminismo desde sus orígenes y sigue sin alcanzarse plenamente, por lo que es totalmente pertinente seguir demandándola, la irrupción de cuestiones asociadas tradicionalmente a la esfera privada supone un importante cambio tanto conceptual como político, que debería ser atendido en la ampliación del proyecto constitucional.

En un reciente artículo en esta misma revista, María Caterina La Barbera alertaba acerca de la situación de desigualdad entre mujeres y hombres mostrando recientes datos alarmantes, tanto de violencia contra las mujeres, como de la desigualdad en la distribución de las tareas domésticas y, por tanto, las dificultades de la conciliación para las mujeres y para su integración laboral, así como las diferencias salariales (La Barbera, 2019). La paridad no ya en el Parlamento, sino en las instancias decisorias -pensemos en nuestro país en esas fotos recurrentes de la apertura del año judicial, compuestas únicamente, año tras año, exclusivamente por varones- nos muestran todavía un panorama lleno de dificultades para las mujeres por el mero hecho de serlo. Muchas de estas dificultades y obstáculos provienen de 
patrones culturales fuertemente anclados en estereotipos de género. Sin duda, las leyes pueden cumplir aquí un papel muy relevante no sólo ya en el reconocimiento de los derechos, sino también, como dijese en su momento Elías Díaz, como instrumentos para el cambio social, con un papel transformador de las relaciones sociales. Los debates y propuestas para la reforma constitucional desde una perspectiva de género, como se evidencian en el trabajo de Itziar Gómez, reflejan ese interés no ya sólo transformador, sino también educativo, introduciendo a nivel constitucional valores y principios en los que se educarán a los jóvenes. No podemos seguir, por tanto, de espaldas a los necesarios cambios que como este $u$ otros -la sostenibilidad, la transición ecológica- comprometen nuestro futuro. Esto es algo que las ilustradas francesas tuvieron muy claro al demandar que ellas también eran ciudadanas. Recordemos, para finalizar y pensar en la pertinencia de plantear el debate que nos sugiere Itziar Gómez, las oportunas palabras de Amelia Valcárcel: «(...) el feminismo es uno de los núcleos principales de la masa crítica que funciona dentro de los sistemas políticos democráticos. Debemos saber y poder reconocer esta herencia para no sentirnos, como habitualmente nos sentimos y sobre todo nos hacen sentir, recién llegadas» (Valcárcel, 1997).

\section{Bibliografía}

Benhabib, S. (1992). Situating the Self. Gender Community and Postmodernism in Contemporary Ethics. Cambridge: Ed. Polity Press.

Bergallo, P. (2011). Cambio constitucional, reproducción, derechos. En R. Gargarella (ed.) La Constitución en 2020. Buenos Aires: Siglo XXI.

Costa, M. (2016). Feminismos jurídicos. Buenos Aires: Ed. Didot.

La Barbera, M. (2019). Igualdad entre mujeres y hombres. Eunomía. Revista en Cultura de la Legalidad, 16, pp. 233-242.

Osborne, R. (1996). ¿Son las mujeres una minoría? Isegoría. Revista de Filosofía moral y política, 14, pp. 79-93.

Pateman, C. (1995). El contrato sexual. Barcelona: Ed. Anthropos.

Phillips, A. (1995). The Politics of Presence. Oxford: Oxford University Press.

Puleo, A. (1993). La llustración olvidada. La polémica de los sexos en el SVIII. Madrid: Ed. Anthropos.

Sánchez, C. (2001). Genealogía de la vindicación. En E. Beltrán y V. Maquieira (coord.), Feminismos. Debates teóricos contemporáneos (pp. 17-74). Madrid: Alianza Editorial.

Scales, A. (1986). The Emergence of Feminist Jurisprudence: An Essay. The Yale Law Journal, 95, pp. 1373-1403.

Sevilla, J. (2004). Mujeres y ciudadanía: La democracia paritaria. Valencia: Ed. Institut Universitari d'Estudis de la Dona.

Valcárcel, A. (1997). La política de las mujeres. Valencia: Ed. Cátedra feminismos. 